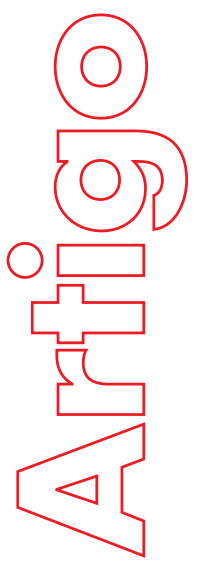

\title{
CARTOGRAFIA E TURISMO NO ESPACO RURAL NO SUL DO BRASIL: O CASO DE JOINVILE EM SANTA CATARINA
}

\author{
Marinês da Conceição Walkowski \\ Paola Rebollar \\ Crisley Silveira Raitz \\ Carlos Loch
}

p. $27-48$

revista

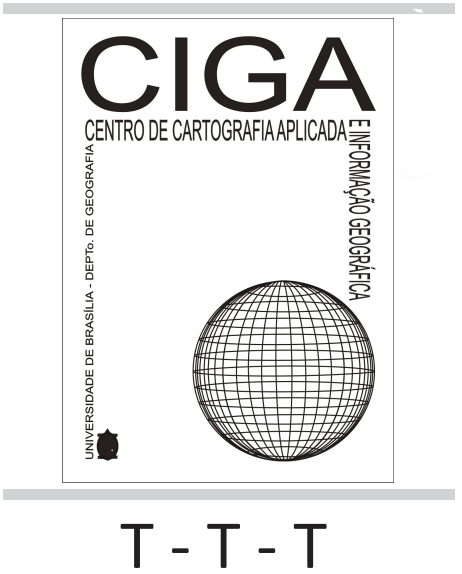

Revista E letrônica: Tempo - Técnica - Território, v.3, n.1 (2012), p. 27:48 ISSN: 2177-4366. 


\section{CARTOGRAFIA E TURISMO NO ESPAÇO RURAL NO SUL DO BRASIL: O CASO DE JOINVILE EM SANTA CATARINA}

\section{Marinês da Conceição Walkowski}

Bacharel em Turismo, Doutorado em Arquitetura e Urbanismo pela Universidade de Santa Catarina, Brasil (2012).

E-mail:

marinesw@yahoo.com.br

\section{Paola Rebollar}

Historiadora, Doutoranda em Informações Espaciais (POLIUSP-BR/IRD-FR), PósDoutoramento em Engenharia Civil pela Universidade de Santa Catarina, Brasil (2012).

E-mail:

Paola.rebollar@gmail.com

\section{Crisley Silveira Raitz}

Geógrafa, Mestranda em Arquitetuta e Urbanismo pela Universidade de Santa Catarina, Brasil (2012).

E-mail:

crisleiraitz@gmail.com

\section{Carlos Loch}

Professor, Dr. Departamento de Engenharia Civil pela Universidade de Santa Catarina, Brasil.

E-mail:

loch@ecv.ufsc.br 


\section{CARTOGRAFIA E TURISMO NO ESPAÇO RURAL NO SUL DO BRASIL}

RESUMO: O turismo é uma atividade econômica importante em muitos países. Existem diferentes modalidades turísticas, dentre as quais podemos destacar o turismo em espaços rurais. Esta modalidade turística vai ao encontro da necessidade de integrar conservação ambiental as atividades agrícolas de forma multifuncional visando o desenvolvimento rural sustentável. O espaço rural sul brasileiro apresenta potencial para esta atividade em função das significativas belezas paisagísticas, riquezas culturais relacionadas aos saberes locais e a estrutura fundiária baseada em pequenas propriedades familiares cuja viabilidade econômica demanda a variação das atividades de forma pluriativa. No entanto, para que este potencial possa ser aproveitado é necessário dispor de informações sistematizadas e espacializadas que permitam ao usuário acessar e desfrutar dos destinos e equipamentos rurais. Neste contexto, o objetivo deste trabalho é demonstrar a aplicabilidade da cartografia derivada de produtos do sensoriamento remoto para o planejamento turístico a nível municipal. Para tanto, uma amostra piloto foi estabelecida no município de Joinville, região nordeste de Santa Catarina. A partir de fotografias aéreas em escalas de 1:1.000, fornecidas pela Prefeitura Municipal de Joinville, nas quais foram identificados por fotointerpretação as propriedades com potencial para o turismo da área amostral. Utilizando o software ArcGis 10 foi elaborado um sistema de informações geográficas que possibilitou a construção de mapas temáticos. Os resultados apontaram para o potencial das imagens de alta resolução e grande escala para o planejamento turístico quando o objetivo é a identificação das famílias que podem ser incorporadas nesta atividade, bem como, para o desenvolvimento de mapas para divulgação do produto turístico local.

Palavras chave: Cartografia; Sensoriamento Remoto; Turismo no Espaço Rural; Joinville.

ABSTRACT: Tourism is an important economic activity in many countries. There are different types of interest, among which we highlight tourism in rural areas. This type tourist meets the need to integrate environmental conservation activities in a multifunctional agriculture for rural development sustainable. The rural southern Brazil has the potential for this activity as a function of significant scenic beauty, rich culture and local knowledge related to the agrarian structure based on small family farms whose economic viability requires the variation of activities so pluriativa. However, for this potential can be tapped is a need for systematic information and spatialized allowing the user to access and enjoy the rural destinations and equipment. In this context, the objective is to demonstrate the applicability of mapping products derived from remote sensing for tourism planning at the municipal level. To this end, a pilot sample was established in the city of Joinville, Santa Catarina northeast. From aerial photographs at scales of 1:1,000, provided by the Municipality of Joinville, in which were identified by 
photointerpretation properties with potential for tourism in the sample area. Using ArcGIS software was developed 10 a geographic information system that enabled the construction of thematic maps. The results showed the potential of high resolution images and large-scale tourism planning when the goal is to identify families that may be incorporated in this activity, as well as for the development of maps for dissemination of the local tourist product.

Keywords: Cartography, Remote Sensing, Rural Tourism, Joinville.

RESUMEN: El turismo es una actividad económica importante em muchos países. Hay modalidades turísticas diferentes, entre los que podemos destacar el turismo en las zonas rurales. Esta modalidad turística tiene la necesidad de integrar conservación ambiental y actividades agrícolas de forma multifuncional visando el desarrollo rural sostenible. El sur rural oferece potencial para esta actividad sobre la base de gran beleza paisagística, riquezas culturales relacionadas con el conocimiento local y la estructura de la tierra basada en pequeñas propriedades familiares cuya viabilidad económica demanda la variación de forma pluriativa. Sin embargo, para que este potencial puede ser aprovechado es necesario información sistematiza y especializadas permitiendo al usuário acceder y disfrutar de destinos y equipamiento rural. En este contexto el objectivo de este trabajo es demostrar la aplicabilidad de la cartografia derivada de productos de teledetección para el planificación turístico a nível municipal. Con este fin, se estabeleció una muestra piloto en el municipio de Joinville, región nordeste de Santa Catarina. De fotografías aéreas a escalas de 1:1000, proporcionadas por la Prefeitura Municipal de Joinville, en el que identificaron por fotointerpretación propriedades con potencial para el turismo de la zona aérea muestra. Mediante el software ArcGris 10 se ha desarrollado un sistema de información geográfica que permite la construcción de mapas temáticos. Los resultados señalaron el potencial de imágenes de alta resolución y gran escala para el planificación turístico cuando la meta es la identificación de las famílias que pueden ser incorporadas en esta actividad, así como para el desarrollo de mapas para la divulgación del producto turístico local.

Palavras chave: Cartografía; Teledetección; Turismo rural; Joinville.

\section{INTRODUÇÃO}

A evolução da sociedade aliado aos diversos desenvolvimentos tecnológicos ocorridos no último século trouxe um novo rumo ao planejamento por intermédio dos sistemas computadorizados.

Muitos países vislumbram no turismo um elemento vital na tentativa de se equilibrar economicamente. Outros, após sofrerem as consequências da degradação 
ambiental, passaram por um processo de conscientização e de valorização das iniciativas endógenas e utilizam o turismo como uma ferramenta de gestão do território.

O turismo é um fenômeno considerado complexo que se inter-relaciona com diversos elementos que o compõe. Trata-se de uma atividade multidisciplinar que requer uma gama de informações e envolve diferentes áreas do conhecimento como: a geografia, a arquitetura e o urbanismo, a economia, entre outros. Para o planejamento adequado desta atividade são necessários investimentos em informações de qualidade.

Neste sentido, a cartografia para o turismo e o uso do sensoriamento remoto, auxiliando na geração de informações de qualidade, permitindo assim, dispor uma ferramenta de mensuração dos possíveis efeitos gerados pelo turismo no território e o planejamento de ações futuras.

O planejamento de um destino turístico, considerando todas as dimensões que afetam o desenvolvimento local, requer um amplo conhecimento da área de estudo. Desta forma, o presente artigo visa demostrar o potencial da aplicabilidade da cartografia, por meio do uso de fotografias aéreas e da fotointerpretação para atividade turística no espaço rural de Joinville.

\section{CARACTERIZAÇÃO DE TURISMO}

O turismo pode ser entendido como um fenômeno social, que promove a interação com as dimensões econômicas, culturais, ambientais e políticas.

Os principais conceitos internacionais trazem como elementos fundamentais do turismo a relação entre: homem, espaço e tempo. Sua evolução esteve ligada ao desenvolvimento industrial e energético, incluindo a revolução industrial o carvão, a máquina a vapor, que possibilitaram a melhoria nos meios de transporte e a mobilidade dos recursos humanos (SMITH; BRENT, 2001).

Uma definição deste fenômeno é a apresentada pela Organização Mundial de Turismo, segundo a qual o turismo compreende "as atividades de pessoas que viajam para lugares afastados de seu ambiente usual, ou que neles permaneçam por menos de um ano consecutivo, a lazer, a negócio ou por outros motivos" (OMT, 2003, p. 20).

De acordo com Pires (2009), o desenvolvimento da atividade turística depende de um conjunto de diferentes fatores que devem ser observados de maneira sistemática, já que estes elementos estão inter-relacionados, interdependentes e se desenvolvem de forma dinâmica e integrada. 
A atividade turística vem evoluindo nos últimos anos, sobretudo nos países em desenvolvimento e nas economias emergentes. Espera-se gerar diretamente mais de 2 milhões de novos empregos, com um aumento de $2 \%$ nas exportações de visitantes e crescimento de 3,5\% no investimento ao longo do ano de 2012, principalmente nas economias emergentes como Brasil, Rússia, Índia e China. Cada vez mais os países do Sudeste da Ásia e da América Latina têm alimentando a demanda de lazer. Surgem então, investimentos efetuados por programas de agências bilaterais e multilaterais, relacionado às estratégias de redução da pobreza e geração de empregos (WTTC, 2012).

O turismo representa algumas receitas substanciais para a economia e pode resultar em impactos tanto negativos quanto positivos ao ambiente. A partir dos anos 90, muitos países começaram a se preocupar com o chamado turismo de massa e passaram a desenvolver planos de turismo e programas para áreas de proteção ambiental. Isto foi feito, por exemplo, no Canadá e nos EUA, em parques nacionais dentro dos quais o turismo é um elemento importante. Na Europa, a Espanha está entre os principais países que investem em energias renováveis em todo o mundo, fruto de diversas discussões e que se refletem em qualidade de vida para os residentes e visitantes (WTTC, 2012; LEMOS et al, 2012).

O início da atividade turística no Brasil, assim como em outros países, esteve vinculado à exploração do litoral, por meio do chamado turismo de massa. Para Bursztyn et al (2009); Pires (2002); e Ruschmann (1999), um exemplo de turismo de massa são os grandes empreendimentos (resorts) que acabam provocando a especulação imobiliária e a descaracterização da cultura local. Este fato fez com que algumas comunidades lutassem por seus direitos, resultando na criação de um turismo alternativo, elevando a qualidade de vida e a autoestima das populações locais.

Dentre os segmentos de turismo mais relevantes encontram-se:

a) Turismo Rural (ou agroturismo): conjunto de atividades desenvolvidas, comprometidas com a produção agropecuária, agregando valor a produtos e serviços, resgatando e promovendo o patrimônio natural e cultural das populações rurais;

b) Turismo cultural: conjunto de atividades que se baseia na utilização de recursos culturais (arte, história e costumes) de um território com a finalidade de conhecimento, preservação e fomento; 
c) Turismo de aventura: pratica de atividade de aventura de caráter recreativo e não competitivo como, por exemplo, a prática do rafting, passeios a cavalo, caiaque, etc.

d) Ecoturismo: atividade turística que utiliza, de forma sustentável, o patrimônio natural e cultural, incentivando a conservação e a formação de uma consciência ambientalista, através da interpretação do ambiente promovendo o bem estar das populações envolvidas.

e) Turismo étnico: atividade turística que envolve a vivência de experiências autênticas e o contato direto com os modos de vida e a identidade de grupos étnicos (MTUR, 2007; PIRES, 2002).

Observa-se na atualidade que a atividade turística tem sido cada vez mais promovida por iniciativa endógenas, locais e regionais, que valorizam aspectos significativos do território. Dentre essas iniciativas, cabe aqui ressaltar o do turismo em espaços rurais.

A expressão "turismo no espaço rural" caracteriza-se por um conjunto de atividades, dentre quais se destacam o agroturismo, ecoturismo, turismo de aventura, entre outros. Neste sentido, torna-se mais abrangente e menos ambígua do que apenas “turismo rural” (PORTUGUEZ, 2002).

O turismo assume diferentes características de acordo com cada configuração sócio espacial de modo que não se pode falar de um turismo rural, mas sim em um conjunto de práticas turísticas no espaço rural. Este espaço está sendo moldado por mudanças tecnológicas e culturais que transformaram as relações entre pessoas e seus ambientes em diversas regiões do planeta. É esperado que nestes locais sejam produzidos alimentos baratos e em abundância e, que ao mesmo tempo, sejam considerada a qualidade da paisagem rural, o bem-estar dos animais de criação e a saúde dos agricultores e consumidores (EL FEKI, 2000). A integração destes objetivos pode ser denominada Desenvolvimento Rural Sustentável. Neste contexto, o turismo no espaço rural pode ao encontro da necessidade de integrar a conservação ambiental as atividades agrícolas de forma multifuncional visando o desenvolvimento rural sustentável.

\section{MULTIFUNCIONALIDADE NA AGRICULTURA}


O espaço rural tem sofrido mudanças com relação ao processo produtivo, por novas formas de divisão social e territorial do trabalho, produzindo mudanças nos hábitos de vida e nas relações sociais. A visão que predomina do rural é a de que está reduzido ao agrícola e também carente de serviços de água, coleta de lixo, tratamento de esgoto, energia elétrica, bem como, de políticas adequadas (SILVA, 1998). Existem famílias que vivem nos espaços rurais que tem dificuldades na geração de renda monetária na agricultura. Na maioria dos casos, isso se traduz em pobreza rural, indicando uma grande precariedade das fontes não agrícolas de geração de renda no interior dos estabelecimentos (ABRAMOVAY, 2002).

Para contornar estes problemas nos espaços rurais, as atividades agrícolas devem apresentar caráter multifuncional. Este caráter se refere ao conjunto dos produtos e serviços propiciados pela atividade agrícola em benefício da economia e da sociedade como um todo.

A agricultura pode exercer três funções: econômica (relativa a sua importância para sustentar o funcionamento e crescimento das economias dos países, bem como a demanda por insumos, mão-de-obra, serviços e capital financeiro); ecológicas (relativa a forma como todos os sistemas agrícolas e de aproveitamento da terra repercutem diretamente nos componentes e no funcionamento dos ecossistemas); e sociais (relativa a manutenção e dinamismo das comunidades rurais no que se refere a qualidade de vida e aproveitamento dos conhecimentos locais) (ABRAMOVAY, 2002; SILVA, 1999).

A multifuncionalidade é uma condição necessária para a ocorrência de sinergia, por meio da combinação de recursos (inputs) ou de mercadorias, como produtos e serviços disponíveis. Isto gera efeitos multiplicadores e a combinação de novas atividades de desenvolvimento rural e as atividades em curso pode levar a um 'upgrade' ou revalorização dos recursos existentes (e atividades), resultando em reduções de custos (KNICKEL; RENTING, 2000).

Para Gomez-Limon et al (2012), o conceito de multifuncionalidade surgiu na União Europeia no final do século passado (1998/1999) para se referir à vasta gama de produtos e serviços que o sector agrícola fornece à sociedade. Esta variedade de produtos e serviços inclui aqueles que podem ser vendidos em mercados existentes, como alimentos e fibras, bem como outros que são fornecidos sem qualquer compensação monetária, porém com algum tipo de benefícios ambientais, sociais ou 
territoriais como, por exemplo, a biodiversidade ecológica, manutenção das aldeias e tradições rurais, paisagens rurais, etc).

No Brasil, a primeira menção ao termo multifuncionalidade na agricultura e do território ocorreu durante a ECO-92, no Rio de Janeiro, e revelou uma preocupação com um rural não exclusivamente agrícola e com os significados não exclusivamente produtivos da prática agrícola. A noção de multifinalidade da agricultura surge como uma nova visão que integra a agricultura a projetos de desenvolvimento no contexto de busca de soluções para as "disfunções” do modelo produtivista e inova ao induzir uma visão integradora das esferas sociais na análise do papel da agricultura e da participação das famílias no desenvolvimento local (CARNEIRO, 2002).

A multifuncionalidade está vinculada a noção de que a atividade agrícola assegura simultaneamente diversas funções econômicas, sociais, espaciais e ambientais, possibilitando repensar o papel do espaço. Neste sentido, surgem atividades não agrícolas em áreas peri urbanas, com capital social acumulado, valor de paisagem e outros atrativos que se desenvolvem no território (MOLLARD, 2006; ABROMAY, 2002; CAMMARATA, 2006).

O turismo também é visto como atividade não agrícola e tem possibilitado uma nova dinâmica com a vinda de visitantes aos municípios rurais, dando a oportunidade para os agricultores explorarem suas propriedades por meio de novas atividades que, não somente a agricultura e a pecuária, mas também a prestação de serviços. Porém, o espaço rural carece de informações de qualidade que resultem no reconhecimento de novas demandas para impulsionar a qualidade de vida destas famílias.

\section{GERAÇÃO DE PRODUTOS CARTOGRÁFICOS DIGITAIS PARA O TURISMO CARTOGRAFIA PARA O TURISMO}

A cartografia como um importante instrumento de planejamento e elaboração de projetos turísticos.

Por meio da cartografia é possível obter informações com maior confiabilidade para o planejamento turístico em função das diversas possibilidades de cruzamento de uma gama de informações complexas, através de um Sistema de Informações Geográficas e da precisão que a cartografia voltada ao planejamento possibilita (DUQUE; MENDES, 2006). Ainda, segundo os autores, a cartografia auxilia no 
diagnóstico e na elaboração do produto turístico, por meio do levantamento de todas as informações relevantes ao planejamento, como por exemplo, o levantamento das potencialidades, dos atrativos turísticos (históricos, naturais, culturais, sociais, entre outros), o público-alvo, o mercado potencial, equipamentos turísticos, infraestrutura básica e a realidade social e econômica da comunidade trabalhada.

Segundo Loch e Erba (2007, p. 94), “os Sistemas de Informação Geográfica (SIG) são ferramentas auxiliares que permitem parametrizar modelos de planejamento e visualizar os dados de forma gráfica (ou cartográfica), tornando-os de mais fácil compreensão”.

Para Martinelli (2006) e Duque (2006), com o surgimento dos satélites e dos computadores, a cartografia passou a ser vista também como um Sistema de Informações Geográficas com função de armazenamento, recuperação, análise e a representação de informações sobre lugares. Estas informações podem ser obtidas por meio de séries históricas, auxiliando na tomada de decisões e possibilitando simulações da realidade, a construção de cenários futuros que podem interferir na paisagem e no espaço como um todo (MOURA, 2001; ARIZA, 2002 ; LANG; BLASCHKE, 2009).

A utilização de imagens aéreas é fundamental para se ter conhecimento da realidade de um local. Nas imagens são encontrados dados relevantes como à declividade, tipo de vegetação, tipo de solo, hidrografia, entre outros. O trabalho de fotointerpretação deve ser complementado e certificado pelo trabalho em campo que possibilita mostrar e simbolizar os elementos que não são identificados em fotografias ou outros materiais e documentos disponíveis, sendo indispensável também o levantamento topográfico que tem por objetivo certificar, retificar e amarrar as informações obtidas nas imagens aéreas. Dessa forma o sensoriamento remoto e o trabalho de campo se complementam e quanto maior a qualidade do material do sensoriamento remoto, menor será a necessidade de atividades de campo.

O mesmo se aplica com a cartografia, onde a visualização não se refere somente à concepção do mapa ou à tecnologia empregada em sua elaboração, mas principalmente a sua finalidade. Dessa forma, a visualização cartográfica faz uso da cartografia digital e de sistemas de informação geográfica para subsidiar a criação de mapas estruturados em ambientes interativos digitais (RAMOS, 2005; RHODY, 2012).

No turismo é possível simular a ocupação irregular em áreas de preservação permanente e o aumento de construções em terreno de marinha, subsidiando não 
somente a questão ambiental, mas também gerando insumos para o planejamento turístico.

A cartografia para o planejamento turístico pode ser utilizada para verificação da demanda, levantamentos físicos dos locais e disposição de equipamentos e serviços etc. Já, a cartografia para uso do turista, por ela denominada de cartografia turística, deve explicar com clareza e simplicidade as informações através dos mapas, a partir do “conjunto de significados representados neste mapa turístico, através dos signos (simbologia), orientação e escala, que o visitante irá se guiar para conseguir chegar ao lugar desejado com mais facilidade e entendimento” (ULLER, 2010, p. 49).

Para esta pesquisa, será demonstrado a aplicabilidade da cartografia para o planejamento turístico no espaço rural de Joinville à partir da fotointerpretação de imagens aéreas.

\section{CARACTERIZAÇÃo DA ÁREA DE ESTUdO E POTENCIAL PARA O TURISMO}

Em Santa Catarina, há um destaque para o Município de Joinville, localizado ao norte do Estado. O Município encontra-se distante 188 km da capital de Florianópolis e é considerado um grande centro de negócios e eventos que tem atraído diversos visitantes. Abaixo, é demonstrado o mapa de localização e a amostra da pesquisa.

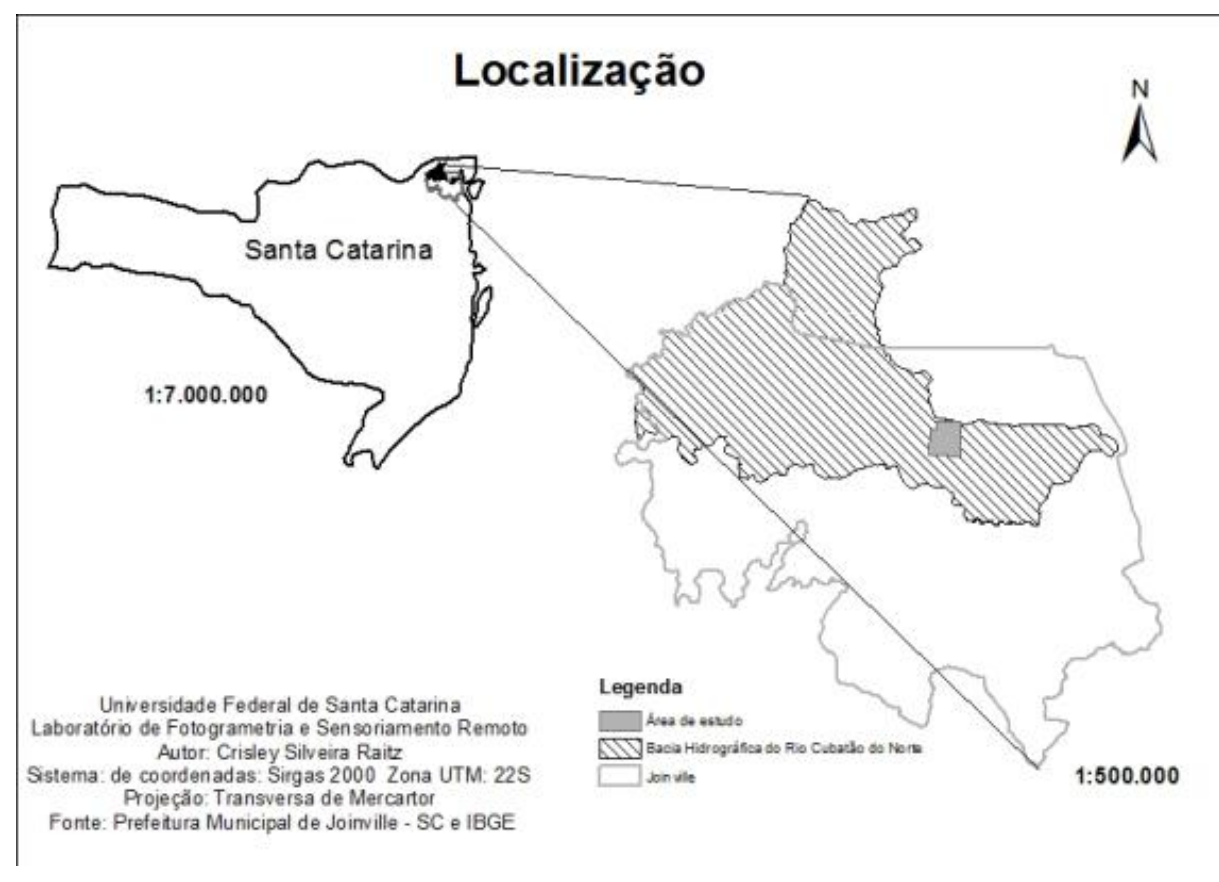


Figura 1. Localização de Joinville.

Elaborado com base na PMJ (2012) e IBGE (2008).

O município foi colonizado em 9 de março de 1851 na região da Dona Francisca. É considerada a maior cidade do estado com 1.134,03km², responsável por $20 \%$ das exportações e o $3^{\circ}$ polo industrial da região sul. O principal acesso é pela BR101, em direção ao norte para Curitiba e São Paulo e ao sul para Itajaí, Florianópolis e Porto Alegre. O município possui uma diversidade étnica em seu processo de colonização, representada por uma população luso-brasileira e negra, composta por germânicos (alemãs, suíços, noruegueses, austríacos, suecos, dinamarqueses, belgas, holandeses), franceses e italianos. O clima na região é úmido a superúmido. O releve se desenvolve sobre terrenos da Serra do Mar e uma área de sedimentação costeira. Em relação à vegetação, se caracteriza pela Mata Atlântica e Manguezais. São mais de 60\% $\left(680 \mathrm{~km}^{2}\right)$ de Floresta Ombrófila Densa e $36 \mathrm{~km}^{2}$ de manguezais (IPPUJ, 2009).

Em relação ao ambiente natural, o município se destaca pela APA (área de Proteção Ambiental) da Serra Dona Francisca, cujo objetivo é a proteção dos recursos hídricos integrados ao desenvolvimento econômico da região. Atualmente está sendo elaborado um plano de manejo da APA, no qual também inclui atividades turísticas. O bairro Dona Francisca encontra-se no distrito de Pirabeiraba e teve sua ocupação associada à implantação da Estrada Serra Dona Francisca, que inicialmente serviu de ligação ao Planalto Norte do Estado, no período colonial. Dona Francisca destaca-se pela paisagem rural: plantações de bananas cortadas por uma estrada de barro, pastos verdes, construções antigas ao fundo, cachoeiras e rios de águas claras (IPPUJ, 2011). Também estão inseridos em seus limites outras Unidades de Conservação: Estação Ecológica, Parque Municipal e Reserva Particular do Patrimônio Natural.

Além do potencial natural, o município também se destaca pela arquitetura neoclássica do século 19, com construções em estilo enxaimel, ainda presente no meio rural e urbano. Ao todo, Joinville possui sete imóveis tombados pela União através do IPHAN, sendo 41 imóveis tombados pelo Estado e 58 imóveis tombados pelo município, entre outros em andamento. 


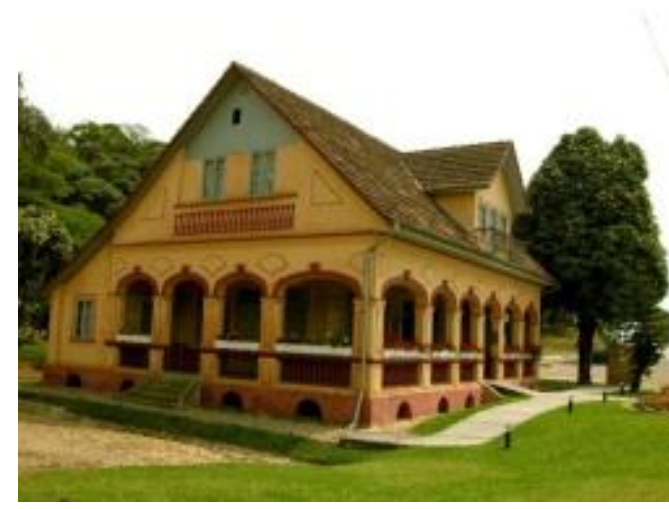

Figura 2: Casarão Kruger. Fonte: PROMOTUR, 2011.

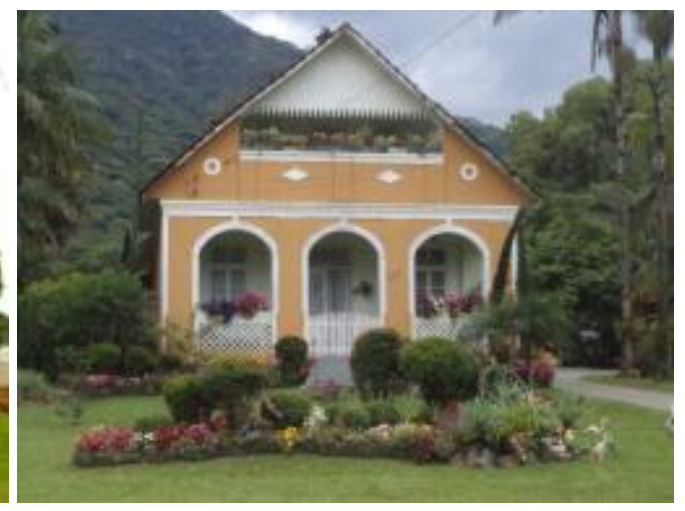

Figura 3: Casarão estilo colonial. Fonte: Dados do autor, 2011.

O meio rural, está representado pela agricultura familiar, onde 97\% das propriedades possuem menos de 50 hectares e a produção varia entre o cultivo de arroz irrigado, banana e hortaliças, presentes em uma área de 89.549ha que se divide em lavouras, reflorestamentos, pastagens e florestas. Além disso, também há um destaque para a pscicultura, pesca artesanal, apicultura e as agroindústrias. Outra atividade que tem se desenvolvido no espaço rural é o turismo rural com destaque para as seguintes regiões turísticas: Estrada Bonita, Piraí, Quiriri, Dona Francisca (com as estradas rurais do Pico, da Prata, do Izaack, do Rio do Júlio e da Mildau) e recentemente a Estrada da Ilha que ainda está sendo diagnosticada (IPPUJ, 2009). Outro destaque é o projeto de turismo pedagógico que tem possibilitado as crianças da região vivenciarem os hábitos e costumes do espaço rural e tem gerado um fluxo significativo de visitantes ao longo do ano na propriedade. Sendo fundamental, neste sentido, ressaltar o potencial no espaço rural.

\section{MATERIAL E MÉTODO DE AVALIAÇÃO}

O método para avaliação do potencial cartográfico para a atividade turística foi desenvolvido em 3 (três) etapas que são: Identificar uma área considerada de interesse turístico e cujas atividades econômicas fossem diversificadas; fotointerpretação e classificação das unidades de paisagem da amostra selecionada; elaboração dos mapas.

A coleta de dados foi realizada entre julho e dezembro de 2011. Os dados observados em campo foram comparados e fundamentados com os levantamentos oficiais realizados pela Fundação Instituto de Pesquisa e Planejamento para o 
Desenvolvimento Sustentável de Joinville - IPPUJ, em 2011 e com o atual Plano Diretor de Desenvolvimento Sustentável do Município de Joinville: Lei no 261 de 28 de fevereiro de 2008.

Para a definição das amostras e, posteriormente, a analise das mesmas utilizarse-á técnicas de fotointerpretação. Fotointerpretação é definida pela Sociedade Americana de Fotogrametria como o ato de examinar e identificar objetos (ou situações) em fotografias aéreas (ou outros sensores) e de determinar o seu significado (LOCH, 2001).

Os materiais que seguem foram utilizados na elaboração da segunda e terceira etapas do processo:

a) Ortofotos do vôo fotogramétrico do ano de 2007, na 1:1.000 cedido pela Prefeitura Municipal de Joinville (PMJ);

b) Base cartográfica vetorizada em meio digital, com referencial geodésico SIRGAS 2000, proveniente de restituição aerofotogramétrica, do ano de 2007 na escala 1:2.000, cedido Prefeitura Municipal de Joinville (PMJ);

c) Software Arcgis, versão 10 (ESRI, 2011);

d) Base cartográfica do IBGE (2008).

Os software ArcGis (ESRI, 2011) foi utilizado para cruzar os arquivos raster (fotografias aéreas) com os arquivos vetoriais. E a partir desses arquivos e da utilização de técnicas de fotointerpretação foi efetuada a identificação e classificação das unidades de paisagem. Foram criados shapes para as unidades de paisagem identificadas, que foram: agricultura; área construída; $\mathrm{Br} 101$; corpos d’água; hidrografia; perímetro urbano; vegetação nativa; e, vias.

Conforme a escala do material que se tem à disposição, pode-se extrair maior ou menor quantidade de informações. Numa foto de pequena escala, não é possível extrair muitos detalhes; mas, por sua vez, em poucas fotos pode-se podemos analisar uma vasta área, dando ao intérprete uma visão geral da região, apresentando os macro elementos, dos quais se pode extrair, depois, alguns detalhes por indução.

As principais características observadas com base no método de fotointerpretação foram:

a) Cursos d' água: caracterizados por linhas sinuosas contínuas, de trajeto irregular que, segundo suas dimensões e escala da fotografia, podem apresentar ou não 
espelho d’ água. Geralmente os tributários atingem o rio principal formando um ângulo cujo vértice aponta o sentido da corrente;

b) Pântanos e alagadiços: caracterizados por áreas com predominância de contornos curvilíneos, geralmente associados aos cursos d’ água;

c) Vegetação natural: áreas de contorno irregulares e de aspectos variável, de acordo com o tipo e idade;

d) Culturas: caracterizadas por formas regulares ou em faixas, de aspecto variável conforme idade (MARCHETTI; GARCIA, 1988).

Ainda utilizando o software ArcGis 10.0 foram elaborados dois mapas: um de localização da amostra e outro com potencial turístico levantado em campo. Para tanto foram utilizados os arquivos vetoriais passados pela Prefeitura de Joinville (Limites políticos do Município de Joinville e Limites da bacia hidrográfica do rio Cubatão norte - bacia em que a amostra está localizada) e o arquivo vetorial, Limites políticos do estado de Santa Catarina, disponibilizado pelo site do IBGE.

O segundo mapa elaborado foi o de uso e ocupação do solo, para este foram utilizados os shapefiles das unidades de paisagem identificadas a partir das fotografias aéreas. O terceiro elaborado foi do potencial turístico em campo, onde foram utilizados os shapefiles das bacias hidrográficas do município e imagens in loco.

\section{RESULTADOS E DISCUSSÃO}

A partir dos materiais e métodos utilizados nesta pesquisa, foi analisada a seguinte amostra:

Na amostra pertencente à figura 4, e com base em documentos oficiais do município, a principal fonte de renda é a agricultura familiar (67\%), principalmente com a produção pecuária e agrícola. O setor primário de Joinville se destaca pela pequena propriedade familiar, e segundo informações obtidas pela Fundação 25 de Julho no ano de 2010, a estrutura fundiária está baseada predominante em pequenas propriedades com menos de 50 hectares.

Com relação ao uso do solo na propriedade, observou-se que a maioria dos residentes ainda vive da agricultura. Esse resultado é fruto de uma política de desenvolvimento sócio-econômico-ambiental adotada pelo Plano Diretor (Lei nº 261 de 2008) que prevê medidas preservacionistas e de uso adequado no espaço rural, além da 
promoção econômica que visa minimizar os impactos da atividade primária em relação as demais atividades e áreas ambientalmente frágeis.

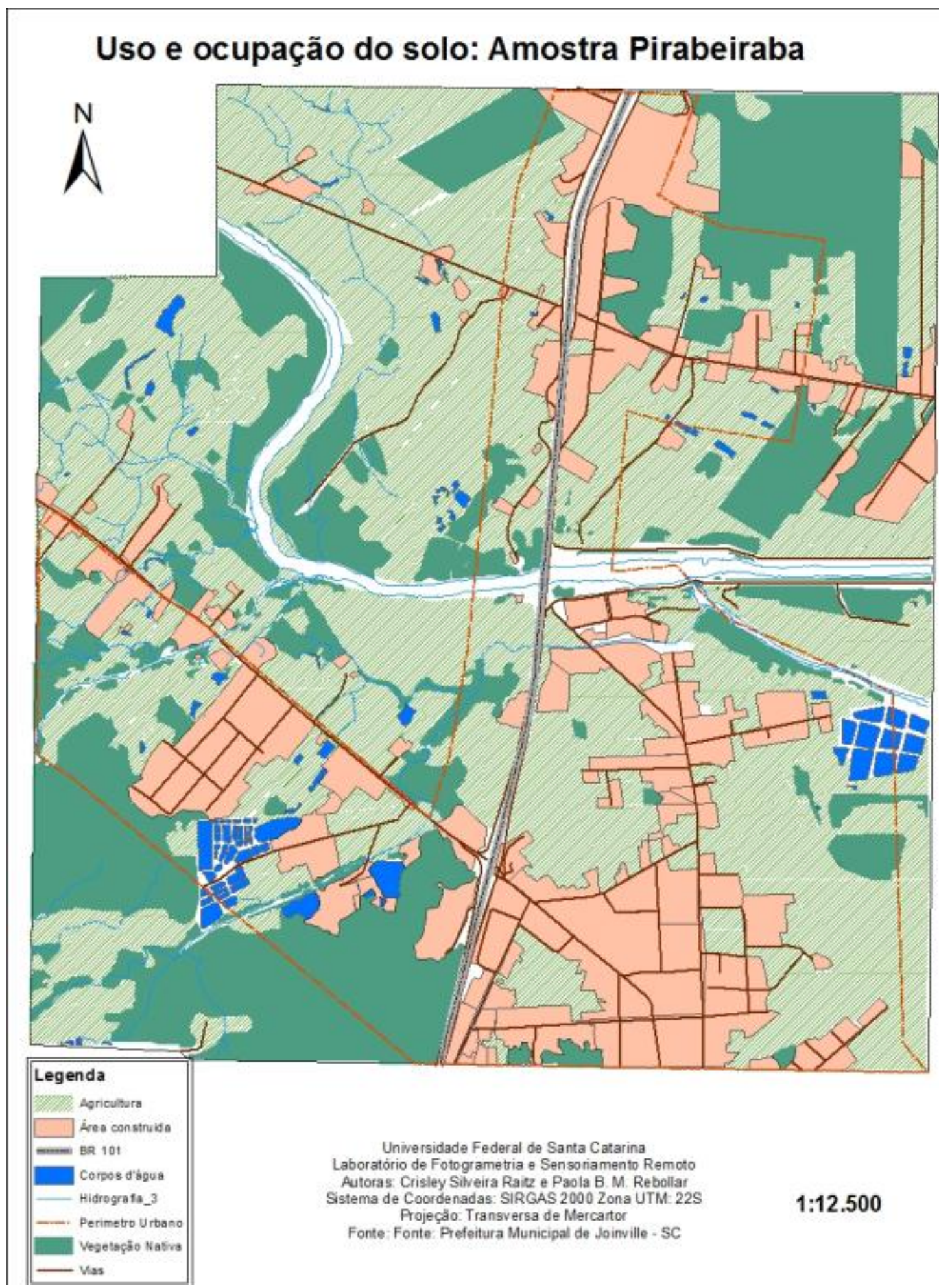

Figura 4: Mapa do uso e ocupação do solo - Amostra Pirabeiraba. Elaborado com base na PMJ (2012). 
O setor agropecuário de Joinville tem relevante participação na produção agrícola da região e abrangência em diversos municípios pertencentes a Secretaria de Desenvolvimento Regional de Joinville. O município é responsável na região por 41\% da produção de arroz, 22\% da produção de banana, 54\% da produção de cana-de-açúcar e $47 \%$ da produção de aipim. Dentre outras atividades agropecuárias se destaca a olericultura, floricultura, produção de palmáceas, piscicultura, avicultura, apicultura, bovinocultura de leite e de corte, pesca artesanal, e o próprio turismo rural. Em relação a este último, o Plano Diretor prevê o estabelecimento de políticas de promoção ao turismo rural e a valorização do patrimônio cultural (IPPUJ, 2011).

$\mathrm{Na}$ amostra pesquisada e com base em pesquisas em campo, observou-se que em função da produção diversificada, há um potencial para o incremento das atividades não agrícolas por meio da venda de produtos e da prestação de serviços. Em função da proximidade das propriedades, observa-se ainda o potencial para o estabelecimento de relações de troca de produtos e cooperação entre os agricultores. Algumas famílias vêm agregando valor por meio da venda direta dos produtos aos visitantes e pelo desenvolvimento de atividades como o turismo pedagógico que vem incrementando a renda familiar, incentivando as escolas para o convívio e a valorização das práticas agrícolas, unidas a aprendizagem. Além disso, também há algumas atividades de lazer como o cicloturismo. Contudo, observa-se ainda que o setor de serviços é pouco explorado em função da existência das agroindústrias artesanais de alimentos, e que não se encontram inseridas em um roteiro.

As propostas voltadas para a atividade turística são poucas e incipientes no espaço rural de Joinville, uma vez que muitos atrativos se encontram em terreno privado e, apesar de estarem no folder de divulgação do município e apresentarem sinalização, encontram-se fechados aos finais de semana, demonstrando que a população local não está sensibilizada para o interesse turístico e para as ações de cooperação e associação. O potencial é evidente pela existência de atrativos naturais como cachoeiras e a própria Serra Dona Francisca, além do patrimônio cultural representado pelas construções enxaimel. Ainda, com base na pesquisa em campo foram identificadas algumas propriedades que se encontram localizadas em regiões consideradas turísticas e que apresentam potencial para o turismo, segundo o mapa abaixo. 


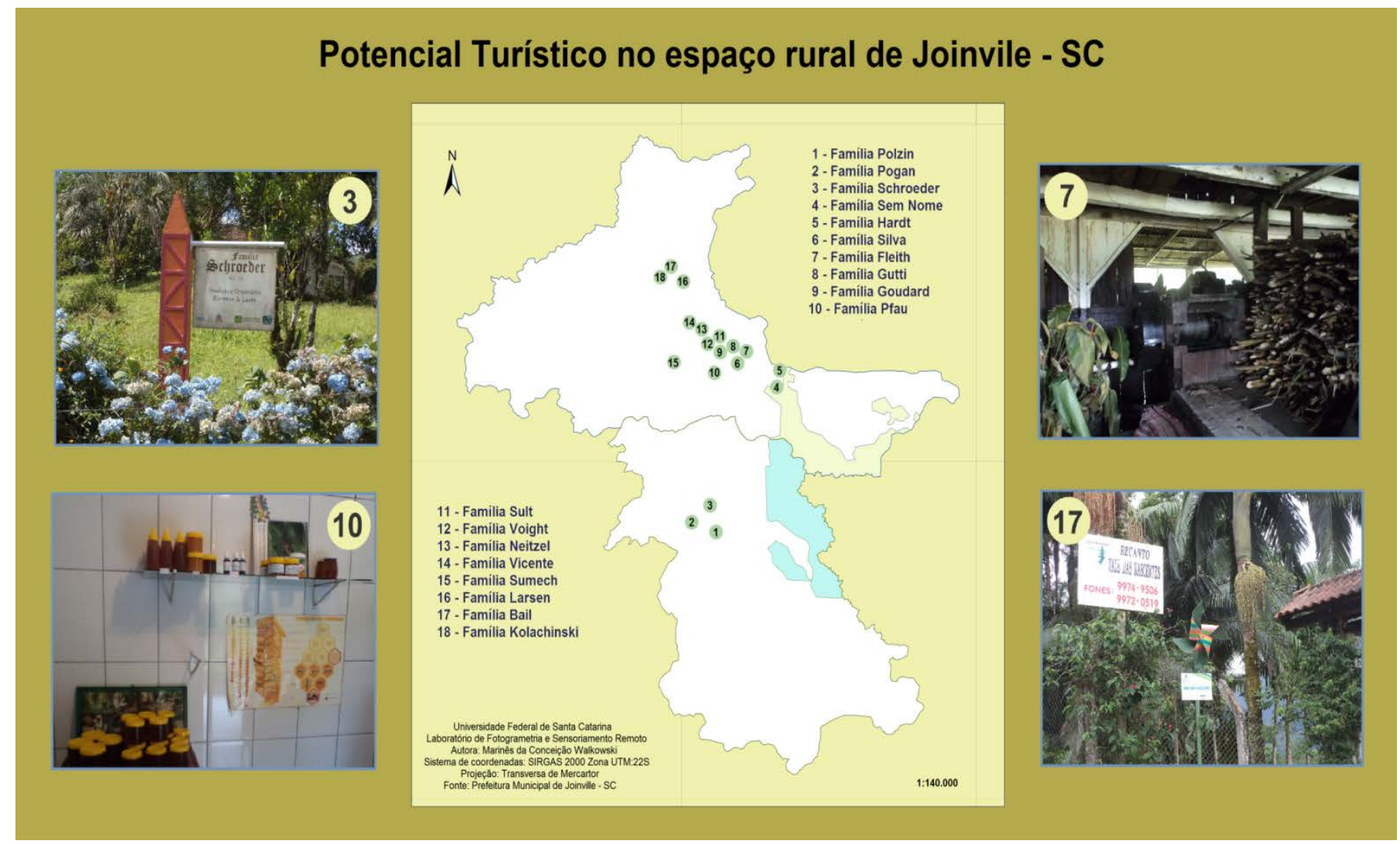

Figura 5: Potencial turístico no espaço rural de Joinville-SC.

Elaborado com base na PMJ (2012).

\section{REFLEXÕES FINAIS}

Pretende-se com a presente proposta de pesquisa, contribuir com o desenvolvimento sustentável e integrado da atividade turística em Joinville - SC, utilizando-se de estratégias que auxiliem na construção de um modelo de gestão pública para áreas de interesse turístico no município.

Estima-se que o turismo, com base nas estratégias de planejamento, possa estimular a valorização da cultura, da paisagem natural, oferecendo um produto de qualidade a diferentes públicos, além de uma oportunidade de geração de renda aos mais diversos setores.

A utilização de ferramentas de Sensoriamento Remoto e Geoprocessamento de dados e a cartografia irão auxiliar na formulação de uma proposta adequada à realidade do município, levando em consideração elementos da paisagem existente no território e que servirão de diferencial competitivo. Além disso, a utilização dessas ferramentas Revista Eletrônica: Tempo - Técnica - Território, V.3, N.1 (2012), 27:48 ISSN: 2177-4366 
serve de instrumento para a tomada de decisão no planejamento turístico para a gestão pública.

O potencial das imagens fotogramétricas para a avaliação local do potencial turístico demonstra o potencial de imagens de satélite que possibilitam uma visão panorâmica e a estruturação de uma proposta de programas de turismo rural sustentável, possibilitar a inserção dos produtos finais no SIG da prefeitura que atenda a demanda turística local.

\section{REFERÊNCIAS}

ABROMAY, R. Subsídios e multifuncionalidade na política agrícola europeia. Economia Rural, vol. 40, n² 2. Abr-jun, 2002.

ARIZA, F. J. Calidad em La producción cartográfica. Espanã: RA-MA, 2002.

BRASIL. Ministério do Turismo. Plano Nacional do Turismo: uma Viagem de Inclusão. Brasília: Ministério do Turismo, 2007.

BURSZTYN, I. et al. Turismo para quem? Sobre caminhos de desenvolvimento e alternativas para o turismo no Brasil. In: BARTHOLO, R.; SANSOLO, D.G.; BURSZTYN, I. Turismo de Base Comunitária diversidade de olhares e experiências brasileiras. Rio de Janeiro: Editora Letra e imagem, 2009, parte I, p.76 91.

CAMMARATA, E. El turismo como práctica social y su papel em La apropiacion y consolidación del território. In: RODRIGUES, A. B. Turismo e territorialidades plurais: lógicas excludentes ou solidariedade organizacional, 2006.

CARNEIRO, M. J. Multifuncionalidade da agricultura e ruralidade: uma abordagem comparativa. In: Org. Roberto José Moreira, Luiz F. de Carvalho Costa. Mundo Rural e cultura. Rio de Janeiro: MAUAD, 2002. p. 65-102.

DUARTE, P. A. Fundamentos da cartografia. 3. ed. Florianópolis: Editora da UFSC, 2006.

DUQUE, R. C; MENDES, C. L. O planejamento turístico e a cartografia. Campinas: Alínea, 2006.

EL FEKI, S. Agriculture and Technology Survey. The Economist - March 25st:3-16, 2000 . 
ESRI - The Gis Software. Disponível em: < http://www.esri.com/products/index.html>. Acesso em 28 de nov de 2011.

FUNDAÇÃO INSTITUTO DE PESQUISA E PLANEJAMENTO PARA O DESENVOLVIMENTO SUSTENTÁVEL DE JOINVILLE - IPPUJ. Disponível em: < http://www.ippuj.sc.gov.br/>. Acesso em 08 de Agosto de 2011.

FUNDAÇÃO INSTITUTO DE PESQUISA E PLANEJAMENTO PARA O DESENVOLVIMENTO SUSTENTÁVEL DE JOINVILLE - IPPUJ. Joinville: Cidade em dados 2009. Caderno. Joinville, PMJ, 2009. 164 p.

FUNDAÇÃO INSTITUTO DE PESQUISA E PLANEJAMENTO PARA O DESENVOLVIMENTO SUSTENTÁVEL DE JOINVILLE - IPPUJ. Joinville: Cidade em dados 2010/2011. Caderno. Joinville, PMJ, 2011, 194p.

FUNDAÇÃO DE PROMOÇÃO E PLANEJAMENTO TURÍSTICO DE JOINVILLE PROMOTUR. Disponível em: < http://www.promotur.com.br/>. Acesso em 20 de Julho de 2011.

GOMEZ-LIMON, José A. Measuring Individual Preferences for Rural Multifunctionality: The Importance of Demographic and Residential Heterogeneity. Journal of Agricultural Economics, Vol. 63, No. 1, 2012. p. 1-24.

INSTITUTO BRASILEIRO DE GEOGRAFIA E ESTATÍSTICO (BASE CARTOGRÁFICA 2008). Município de Joinville. Disponível em: $<$ http:॥www.ibge.gov.br>. Acesso em: 29 de Nov de 2011.

LANG, S.; BLASCHKE, T. Análise da paisagem com SIG. Tradução Hermann Kux. São Paulo: Oficina de textos, 2009.

LEMOS, C. C. Strategic environmental assessment in tourism planning - Extent of application and quality of documentation. Environmental Impact Assessment Review. Disponível em: < journal homepage: www.elsevier.com/locate/eiar>. Acesso em 26 de fev de 2012.

LOCH, C.; ERBA, D. A. Cadastro técnico multifinalitário rural e urbano. Cleveland, Lincoln Institutof Land Policy, USA, 2007, 160 p.

LOCH, Carlos. A interpretação de imagens aéreas: noções básicas e algumas aplicações nos campos profissionais. 4 ed. Florianópolis: UFSC, 2001.

KNICKEL, K.; RENTING, H. Methodological and Conceptual Issues in the Study of Multifunctionality and Rural Development. Sociologia Ruralis, v. 40. $n^{\circ} 4$. Blackwell Synergy, 2000. p. 512-528.

Revista Eletrônica: Tempo - Técnica - Território, V.3, N.1 (2012), 27:48 ISSN: 2177-4366 
MARCHETTI, D. A. B.; GARCIA, G. J. Princípios de fotogrametria e fotointerpretação. 1 ed. (4 Reimpressão), São Paulo: Ed. Nobel, 1988. 257 p.

MARTINELLI, M. Mapas da geografia e cartografia temática. São Paulo: Contexto, 2006. 3 ed.

MOLLARD, A. Multifuncionalidade, externalidades e territórios. In: Eisforia/Universidade Federal de Santa Catarina, Centro de Ciências Agrárias, Pograma de Pós-Graduação em Agroecossistemas. v. 1, n. 1 (jan/jun, 2003) Florianópolis: PPGAGR, 2006.

MOURA, M. C. Uso de sistemas de informações geográficas no planejamento para otimização de rotas de distribuição. Viçosa: UFV, 2001.

WORLD TRAVEL \& TOURISM. Disponível em: <http://media.unwto.org/en/pressrelease/2012-03-08/spain-host-world-tourism-day-2012-under-theme-tourism-andsustainable-energ>. Acesso em 20 de março de 2012.

PIRES, P. dos S. et al. Estruturação de matriz de impactos do turismo: o caso do agroturismo no município de Santa Rosa de Lima/SC. Revista Brasileira de Pesquisa em Turismo v. 3, n. 1, p. 68-89, abril 2009.

Dimensões do ecoturismo. São Paulo: Editora Senac, 2002.

PORTUGUEZ, A. P. Agroturismo e desenvolvimento regional. São Paulo: HUCITEC, 2002.

ORGANIZAÇÃO MUNDIAL DO TURISMO (OMT). Guia de desenvolvimento sustentável. Porto Alegre: Bookman, 2003.

RAMOS, C. S. Visualização cartográfica e cartografia multimídia: Conceitos e tecnologias. São Paulo: Unesp, 2005.

RHODY, B. Interpretación de fotografias y cartografia com fines forestales. Disponível em: <www.fao.org/docrep/24755s/24755s02.htm>. Acesso em 12 de jan de 2012.

RUSCHMANN, D. V. M. Turismo e planejamento sustentável: a proteção do meio ambiente. 5. ed. Campinas, SP: Papirus, 1999.

SILVA, J. G. A nova dinâmica da agricultura familiar. Instituto de Economia. Campinas, SP. Ed. UNICAMP, 1998.

SMITH, V; BRENT, M. Hosts and guests revisited. Tourism Issues for the century. New York: Cognizant Communication Corporation, 2001. 
ULLER, A. S. Cartografia turística: Uma leitura dos mapas temáticos de uso do turista em Ponta Grossa - Paraná. São Paulo, 2010. Tese de doutorado em Geografia da Faculdade de Filosofia, Letras e Ciências Humanas da Universidade de São Paulo. 